\title{
El Dúo Pimpinela en la transición democrática argentina: una escucha política
}

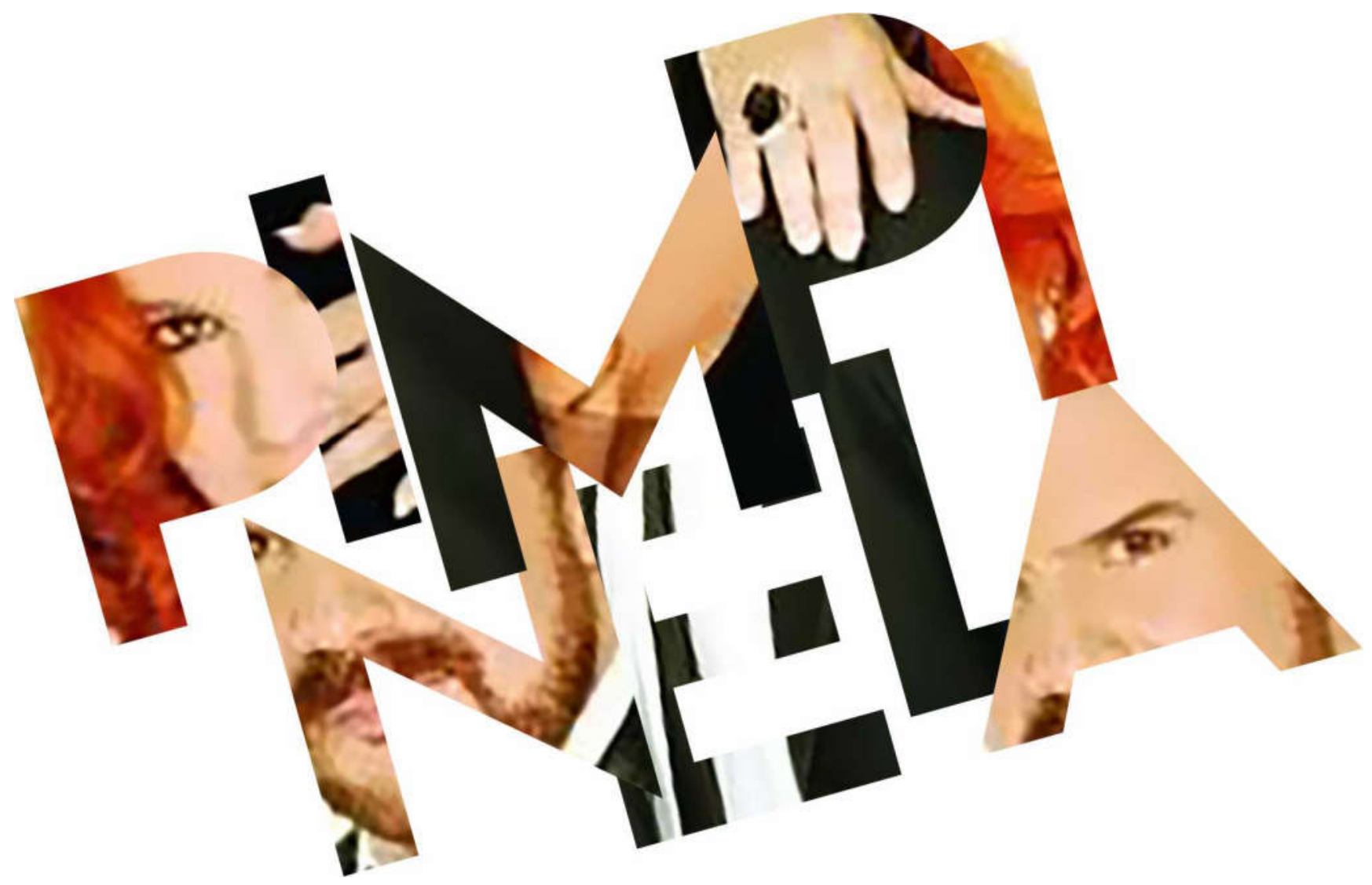

Lucía e Joaquín Galán, Dúo Pimpinela. 2012, fotografia (detalhe).

\section{Claudio F. Díaz}

Mestre em Sociossemiótica e doutor em Letras pela Universidad Nacional de Córdoba (UNC). Professor da Facultad de Filosofía y Humanidades da UNC. Coorganizador, entre outros livros, de Fisuras en el sentido: músicas populares y luchas simbólicas. Córdoba: Recovecos, 2015. claudiofdias@hotmail.com.ar 


\title{
El Dúo Pimpinela en la transición democrática argentina: una escucha política*
}

Pimpinela Dúo in the Argentine democratic transition: a political listening

\author{
Claudio F. Díaz
}

\section{RESUMEN}

En el presente trabajo propongo una escucha en clave política de algunas canciones del Dúo Pimpinela. Estos artistas se hicieron conocidos a principios de la década de los ochenta del siglo pasado con una propuesta innovadora que combinaba los temas y formas musicales de la balada romántica con estructuras dramáticas propias del teatro, para representar escenas basadas en las peleas y rupturas de pareja. Las canciones de pelea, si bien mostraron la capacidad de interpelar masivamente al público, no se han pensado en vinculación con el proceso de transición democrática que se iniciaba en esos años con el debilitamiento de la dictadura, principalmente después de la guerra de Malvinas. Sin embargo, una escucha en clave política se hace posible si se vinculan la crisis de las relaciones entre los géneros, en especial las relaciones matrimoniales, por una parte, con un amplio conjunto de demandas de democratización que caracterizaron el período, por otra. Para fundar esa escucha política, propongo recuperar dos nociones de larga trayectoria en los estudios culturales: la de "inconsciente político", desenvolvida por Frederic Jameson, y la de "estructura de sentimiento", propuesta por Raymond Williams.

PALABRAS CLAVE: Canción popular y política; democracia y género; Dúo Pimpinela.

\section{ABSTRACT}

In this paper, I propose to listen some Pimpinela Dúo songs in a political key. These artists became popularities at the beginning of the eighties of the last century with an innovative proposal that combined the themes and musical forms of the romantic ballad with dramatic structures typical of the theater, to represent scenes based on fights and couple breakups. This fight songs, altought they showed the ability to massively challenge the public, have not been thought of in connection with the democratic transition process that began in those years with the weakening of the dictatorship, mainly after the Falklands war. However, listening in a political key is made possible if two aspects are linked: on the one hand, the crisis in relations between the genders - especially, marital relations - and, on the other, a broad set of demands for democratization that characterized the period. To found this political listening, I propose to recover two notions with a long history in cultural studies: the "political unconscious", developed by Frederic Jameson, and the "sentiment structure", proposed by Raymond Williams.

KEYWORDS: Popular song and politic; democracy and gender; Pimpinela Dúo.

\footnotetext{
* El presente trabajo forma parte de una investigación en curso, realizada en colaboración con la musicóloga Dra. Silvina Argüello, con sede en el Centro de Investigaciones de la Facultad de Filosofía y Humanidades (CIFFyH) de la Universidad Nacional de Córdoba, Argentina. Nota da Editoria: este texto foi inicialmente apresentado, em 8 dez. 2020, no XVII Encontro Estadual de História do Ceará, promovido pela seção cearense da Associação Nacional de História (Anpuh-CE), em debate sobre Música popular \& política: as múltiplas faces das canções, que, sob a coordenação do Prof. Dr. Francisco José Gomes Damasceno, da Universidade Estadual do Ceará (Uece), contou, como outro conferencista, com a participação do Prof. Dr. Adalberto Paranhos, da Universidade Federal de Uberlândia (UFU) e pesquisador do CNPq.
} 
La reflexión académica sobre las relaciones entre música popular y política tiene ya una tradición bastante sólida. Desde diferentes disciplinas (Historia, antropología, sociología, musicología, análisis del discurso, etc.) se ha indagado las muy diversas maneras en que las canciones populares se van articulando con procesos políticos de distinta naturaleza. Así, los estudios sobre el tango o el folclore en diferentes países latinoamericanos, han mostrado, por ejemplo, la manera en que estas músicas y danzas se han articulado con narrativas identitarias nacionalistas, en parte impulsadas por los propios estados en sus procesos de modernización. ${ }^{1}$ Del mismo modo, una buena parte de los estudios sobre el rock de la región muestra su articulación con procesos de contestación o de resistencia ante procesos políticos de distinta índole², y más recientemente algunos trabajos han estudiado fenómenos como la cumbia de una manera similar. ${ }^{3}$

En todos estos antecedentes puede observarse que existen formas muy variadas en que se establece esa relación entre las canciones populares y lo político. En algunos casos, la relación es evidente desde el mismo proceso de producción, cuando las canciones son pensadas como toma de posición tanto estética como política, en la medida en que los artistas (autores o intérpretes) forman parte o apoyan alguna causa públicamente conocida: movimientos político-partidarios, movimientos de derechos humanos, ambientalistas, sindicales, defensa de derechos de minorías, organizaciones sociales de distinto tipo, etc. Un excelente estudio en esa dirección, en el caso de la Argentina, es el libro de Carlos Molinero sobre el Movimiento de la Canción Militante de los sesenta y setenta del siglo pasado. ${ }^{4}$ Pero también pueden estudiarse las derivas políticas de canciones que no tuvieron esa intencionalidad originalmente. En el reciente libro Las múltiples vidas de las canciones, compilado por Abel Gilbert y Martín Liut, se analizan varios casos de este tipo, como es el de la nueva vida que adquirió la cumbia "No me arrepiento de este amor" ${ }^{2}$, que Gilda grabara en 1994, al convertirse en parte de la campaña política del PRO, que llevó a Mauricio Macri a consagrarse como presidente de la Argentina en $2015 .{ }^{6}$ En estos casos, nuevos contextos sociales de recepción, o incluso nuevas

\footnotetext{
1 Ver, por ejemplo, GARCÍA CANCLINI, Néstor. Culturas híbridas: estrategias para entrar y salir de la modernidad. Buenos Aires-Barcelona-México: Paidós, 2001; ZÁNCHEZ PATZY, Mauricio. La ópera chola: música popular en Bolivia y pugnas por la identidad social. La Paz: Plural, 2017; MENEZES, Andreia dos Santos. Pandeiros e bandoneones: vozes disciplinadoras e marginais no samba e no tango. Sao Paulo: Editora Unifesp, 2017.

${ }^{2}$ Ver, por ejemplo, BLANCO, Oscar y SCARICACIOTTOLI, Emiliano. Las letras de rock en Argentina: de la caída de la dictadura a la crisis de la democracia (1983-2001). Buenos Aires: Colihue, 2014; SALAS, Fabio. El grito del amor: una actualizada historia temática del rock. Santiago de Chile: LOM, 1998; LÓPEZ MOYA, Martín de la Cruz, ASCENCIO CEDILLO, Efraín y ZEBADÚA CARBOBELLI, Juan Pablo (coords.). Etnorock: los rostros de una música global en el sur de México. México: Juan Pablos, 2014.

${ }^{3}$ Ver, por ejemplo, SEMÁN, Pablo y VILA, Pablo. Cumbia: nación, etnia y género en Latinoamérica. Buenos Aires: Gorla, 2011.

${ }^{4}$ Ver MOLINERO, Carlos. Militancia de la canción: política en el canto folklórico de la Argentina, 1944-1975. Buenos Aires: Ediciones de aquí a la vuelta, 2011

${ }^{5}$ Video oficial disponible en $<$ https://www.youtube.com/watch?v=8iUkmnLclec>.

${ }^{6}$ Ver GILBERT, Abel y LIUT, Martín (comps.). Las mil y una vidas de las canciones. Buenos Aires: Gourmet Musical, 2019.
} 
versiones de viejos temas, generan las condiciones para la resignificación de las canciones, a veces en términos políticos.

El caso que propongo tratar en este artículo forma parte de este cauce general, pero con una especificidad. Se trata de canciones que en el momento de su circulación primera no fueron percibidas como políticas, porque se trataba de canciones de amor/desamor. Sin embargo, el tratamiento que hacen de esos temas las hace parte de aspectos sustantivos de las luchas simbólicas que con el transcurrir del tiempo fueron percibidas en su plena politicidad. Me refiero a las canciones de pelea del Dúo Pimpinela, que en la primera mitad de los años ochenta del siglo $\mathrm{XX}$, le dieron voz a un malestar de las mujeres con respecto a las relaciones de género, en particular las relaciones matrimoniales, que iría revelando su potencia política en el transcurrir de las décadas siguientes. No se trata entonces tanto de una resignificación de las canciones, sino de la progresiva politización de un área de la vida social que todavía por entonces se consideraba del ámbito de lo privado.

Proponer una escucha política de esas canciones y en esos términos supone, sin embargo, el peligro de caer en el anacronismo de valorar producciones del pasado a partir de debates del presente. Aunque hasta cierto punto ese sesgo de la escucha es inevitable, se puede recuperar algo de la densidad de los sentidos vividos en ese momento alrededor de estas canciones, retomando dos nociones con larga trayectoria en los estudios culturales, pero que todavía muestran ser operativas. Me refiero a la noción de "estructura de sentimiento" propuesta por Raymond Williams7 y a la de "inconsciente político" desarrollada por Frederic Jameson. ${ }^{8}$

\section{Música y política hacia 1982}

En la historia argentina, el año 1982 está fuertemente marcado por lo político. Fue el año en que la Multipartidaria Nacional junto a la CGT, organizaciones estudiantiles y de Derechos Humanos convocaron a grandes movilizaciones contra la dictadura militar. ${ }^{9}$ También fue el año de la guerra de Malvinas, que terminó con la derrota militar en el Atlántico sur. ${ }^{10}$ Este hecho acabó de deslegitimar al gobierno de facto, dando inicio a un proceso de apertura que terminaría al año siguiente con la celebración de elecciones. En ese período se hizo visible un amplio espectro de la producción cultural, incluida la música popular, que se venía politizando, en un sentido muy específico de oposición al autoritarismo, la censura y la falta de libertad. En ese marco, el retorno de Mercedes Sosa, que estaba en el exilio desde 1979, fue un momento

\footnotetext{
${ }^{7}$ Ver WILLIAMS, Raymond: Marxismo y literatura. Barcelona: Península, 1980.

${ }^{8}$ Ver JAMESON, Frederic: Documentos de cultura/Documentos de barbarie. Madrid: Visor, 1989.

${ }^{9}$ La Multipartidaria fue un espacio de acción política que reunía a un conjunto de partidos que se oponían a la dictadura militar (Unión Cívica Radical y Partido Justicialista, entre otros). Se creó en 1981 y se disolvió en 1983, después de recuperada la democracia. El 30 de marzo de 1982, la Multipartidaria, junto a la Confederación General del Trabajo (CGT), organizaciones de Derechos Humanos y organizaciones estudiantiles, convocó a una gran movilización contra la dictadura que reunió a más de 100.000 personas sólo en Buenos Aires.

${ }^{10}$ La guerra de Malvinas comenzó el 2 de abril de 1982, cuando las Fuerzas Armadas Argentinas desembarcaron en las islas, sobre las que el país reclama soberanía pues se encuentran en poder de Gran Bretaña desde 1833. Gran Bretaña envió una gran fuerza expedicionaria para recuperarlas. El 14 de junio las tropas argentinas se rindieron, dando fin al conflicto.
} 
clave. Al regresar, la cantora ofreció una serie de recitales realizados en el Teatro Ópera de Buenos Aires entre el 18 y el 28 de febrero de ese año, seguidos de una gira nacional. ${ }^{11}$ Varias razones convirtieron esos recitales en un hito cultural. Por una parte, el lleno total hacía evidente una vigencia y una continuidad, no sólo de Mercedes Sosa, sino también de toda una serie de formas artísticas y culturales disidentes, a pesar de la censura imperante durante la dictadura. Por otra parte, en esos recitales se grabó un disco en vivo, que sería editado con el título Mercedes Sosa en Argentina. Durante 1983, una vez iniciada la apertura democrática que culminaría con las elecciones de octubre de ese año, cuando llegó a la presidencia Raúl Alfonsín, el disco se convirtió en un gran suceso de ventas. ${ }^{12}$

Lo interesante de esos recitales, así como de la gira y del disco, es que la propuesta de Mercedes Sosa se mostró capaz de interpelar a públicos más amplios que el del folklore, principalmente a sectores jóvenes. De hecho, en los recitales participaron varios músicos de rock, como Charly García y León Gieco, y de las nuevas camadas de folkloristas que también convocaban un público joven, como Antonio Tarragó Ros. De tal manera en esos eventos se expresaba y al mismo tiempo se contribuía a construir una identidad ${ }^{13}$ que se articulaba alrededor de un imaginario cuyas significaciones nucleares eran la libertad, la democracia y los derechos humanos. ${ }^{14}$

Si bien esos recitales de Mercedes Sosa tuvieron mucha visibilidad, no fueron los únicos en esa construcción identitaria. Numerosas peñas y festivales folklóricos, así como recitales y festivales rockeros, antes y después de Malvinas, venían mostrando esta específica articulación entre música y políti$\mathrm{ca}^{15}$. No es de extrañar entonces que un conjunto de canciones de ese período quedaran en la memoria colectiva y parecieran saturar el espacio de la "canción política" de la época: "Sólo le pido a Dios" (León Gieco), "Como la cigarra" (María Elena Walsh), "Todavía cantamos" (Víctor Heredia), "Carta de un León a otro" (Chico Novarro), "Inconsciente colectivo" (Charly García), "La vida y la libertad" (Antonio Tarragó Ros), por sólo nombrar algunas.

\section{Las canciones de pelea del Dúo Pimpinela}

Ese mismo año ocurrió otro fenómeno que tuvo un enorme impacto de masas y sin embargo no ha quedado en la memoria política. Me refiero al lanzamiento del disco Pimpinela, del dúo homónimo, que incluía la canción "Olvídame y pega la vuelta". Esa canción no sólo los llevó a la fama, sino que

\footnotetext{
${ }^{11}$ Sobre el retorno de Mercedes Sosa y sus relaciones con los rockeros, ver DÍAZ, Claudio. Alta Fidelidad: el rock, el folklore... y Mercedes Sosa. Ecos del Folklore, n. 3, Buenos Aires, 2019.

${ }^{12}$ Cf. BRACELI, Rodolfo. Mercedes Sosa: La Negra. Buenos Aires: Sudamericana, 2003, p. 173-181.

${ }^{13}$ Entiendo la identidad como una construcción social, en la que los discursos tienen una importancia clave. Sobre la relación identidad/discursos, ver KALIMAN, Ricardo (comp.). Sociología de las identidades: conceptos para el estudio de la reproducción y la transformación cultural. Villa María: Eduvim, 2013; sobre la relación específica entre música e identidades, ver FRITH, Simon. Música e identidad. In: HALL, Stuart y DU GAY, Paul (comps.). Cuestiones de identidad cultural. Buenos Aires-Madrid: Amorrortu, 2003.

${ }^{14}$ Para el concepto de imaginario social, ver CASTORIADIS, Cornelius. La institución imaginaria de la sociedad. Buenos Aires: Tusquets, 1993.

${ }^{15}$ Algunos ejemplos son El festival de Música Contemporánea de La Falda, que comenzó en 1980, el festival Prima Rock, realizado en septiembre de 1981 o el festival B. A. Rock, realizado en noviembre de 1982. Lo mismo pasaba en el campo del folklore con las giras de grupos como Los Trovadores o el Cuarteto Supay, y con representantes de las nuevas generaciones como Antonio Tarragó Ros.
} 
consolidó un formato que de ahí en más caracterizaría el estilo musical del dúo: las canciones de pelea. “A esa" (1983), “Una estúpida más" (1983), “Ahora decide" (1984) y "Valiente" (1987) ${ }^{16}$ son algunas canciones de ese formato que circularon masivamente en los años ochenta, y que en buena medida siguen vigentes hasta hoy. La respuesta del público fue masiva no sólo en la Argentina, sino en todo el mundo de habla hispana. Según el testimonio de Joaquín Galán el disco Pimpinela vendió en 1983 un millón de copias, solamente en Argentina, y el tema "Olvídame y pega la vuelta" llegó a igualar al tango "La cumparsita" en derechos de autor. ${ }^{17}$

El fenómeno del Dúo Pimpinela, pues, es contemporáneo de ese proceso de politización de la canción popular que mencionaba más arriba, y no paró de crecer hasta bien entrados los noventa. Sin embargo, tal vez por ser parte del mundo de la canción melódico/romántica, habitualmente considerada banal, no ha sido pensado como parte de ese proceso social. A pesar de ello, según el testimonio de Joaquín Galán, cuando Silvio Rodríguez visitó por primera vez la Argentina en 1984, manifestó en conferencia de prensa, y para sorpresa de muchos, que los artistas argentinos más conocidos y queridos en Cuba eran, justamente, los Pimpinela. ${ }^{18}$ Aún con esa popularidad, y en medio de las transformaciones democráticas en curso, era difícil apreciar el aspecto político de estas canciones de desamor y peleas.

Hay dos rasgos que marcan una singularidad del dúo Pimpinela, en los que vale la pena detenerse porque son los que abonan la posibilidad de una escucha política de las canciones de pelea. En primer lugar, su particular dispositivo de enunciación ${ }^{19}$, inédito en el mundo de la canción, principalmente en un género específico dentro de la música popular que denominamos como canción romántica, siguiendo a Ulhoa y Pereira. ${ }^{20}$ Lo que caracteriza a ese tipo de canción, además de formas musicales que arraigan en el bolero y evolucionaron hacia la balada en los años $70^{21}$, es la temática amatoria. Y dentro de esa temática amatoria, muchas canciones abordan las rupturas, los abandonos, los desamores. Más aún, según el relevamiento realizado por María del Carmen De la Peza sobre letras de boleros, hay un amplio predominio

\footnotetext{
${ }^{16}$ Las canciones mencionadas pueden están disponibles en los siguientes links. “Olvídame y pega la vuelta". <https://www.youtube.com/watch?v=fOHrY0jV6Hg>; "A esa". <https://www.youtube.com/watch?v=s NY7AiSjJJM $>$; “Una estúpida más". <https://www.youtube.com/watch?v=tpN3S1aIWyM>; "Ahora decide”. $<$ https://www.youtube.com/watch?v=A9OnoC_9Jis>; "Valiente". <https://www.youtube.com/watch?v=Sm yqBK9chVw>.

${ }_{17}$ Cf. GALAN, Lucía y GALAN, Joaquín. Hermanos: la verdadera historia. Buenos Aires: Planeta, 2017, p. 163.

${ }^{18}$ Cf. idem, ibidem, p. 110 .

${ }^{19}$ Por dispositivo de enunciación entiendo el conjunto de estrategias discursivas orientadas a construir el enunciador, el enunciatario y las relaciones entre ellos. Tales estrategias pueden ser verbales, musicales, de diseño de portadas, elección de repertorios, etc. Para un análisis más detallado, ver DÍAZ, Claudio. Mapas de escucha y dispositivos de enunciación: una aproximación a la producción de sentido en la recepción de músicas populares. In: DÍAZ, Claudio (comp.). Fisuras en el sentido: músicas populares y luchas simbólicas. Córdoba: Recovecos, 2015.

${ }^{20}$ Ver ULHÔA, Martha y PEREIRA, Simone (orgs.). Canção romântica: intimidade, mediação e identidade na América Latina. Río de Janeiro: Folio Digital, 2016.

${ }^{21}$ Sobre las baladas románticas de los setenta, ver MADRID, Alejandro. Más que "tontas canciones de amor": sentimentalismo cosmopolita en la balada romántica de México en los 1970s y 1980s. In: ULHÔA, Martha y PEREIRA, Simone, op. cit.
} 
de las figuras del amor desdichado sobre las del amor feliz. ${ }^{22}$ De tal manera que es más habitual la expresión de sentimientos negativos que positivos. Y esa misma tendencia se observa en las baladas románticas de los sesenta y setenta, que son el antecedente inmediato del dúo Pimpinela, como lo atestiguan clásicos como "Ella ya me olvidó", de Leonardo Fabio; “La distancia”, de Roberto Carlos; “Cuando salí de Cuba”, de Luis Aguilé o "Me amas y me dejas", de Sandro, por sólo nombrar algunos. Pero en esas canciones la ruptura amorosa se aborda desde la expresión lírica de los sentimientos, desde la narración de una historia, desde la interpelación al/la amado/a, o desde una mixtura de esos registros. La novedad de las canciones de pelea es que muestran a la pareja en el momento exacto en que la disputa está ocurriendo. No se narra un hecho que ocurrió, ni se exponen los efectos de ese hecho en los sentimientos del yo lírico. En las canciones de pelea se muestra, o, más bien, se representa el hecho mientras está ocurriendo. De manera que el dispositivo de enunciación de esas canciones se acerca notoriamente al del teatro ${ }^{23}$, o más específicamente a formas del drama cantado como la ópera, la zarzuela o, más contemporáneamente, el musical a la manera de Brodway. Las canciones de pelea son pequeños musicales de tres minutos. Este rasgo hace posible una serie de articulaciones entre la "escena teatral" y la "escena representada" que permite potenciar las relaciones de los personajes entre sí, pero también con el público, generando distintas formas de complicidad. ${ }^{24}$ Pero, además, como se trata de una palabra cantada, la perfomance de los artistas se potencia con el uso de las voces, con las estructuras melódicas, armónicas y rítmicas, con la orquestación, las texturas y la dinámica.

El segundo rasgo que marca la especificidad de las canciones de pelea, tiene que ver con la manera en que se desarrollan y se resuelven los conflictos: en esas disputas de pareja, la voz que siempre se impone es la de la mujer, es decir, la de los personajes que interpreta Lucía Galán. Y esto puede observarse en varios niveles. Por un lado, en las tramas argumentales. En todos los casos la mujer increpa a un varón que está siempre en falta y apenas puede balbucear excusas. Él la abandonó y, al intentar regresar, ella lo expulsa; ella descubre que tiene una amante y lo confronta duramente; ella es la amante y lo increpa por haberla hecho esperar y no cumplir sus promesas; ella le recrimina sus comportamientos violentos que no hacen más que ocultar su cobardía, etc. En contraste con la potencia de los reclamos femeninos, las respuestas del varón son débiles excusas que giran siempre alrededor de un mismo tópico: la búsqueda de emociones, sensaciones, ilusiones, por fuera de la relación de pareja. Pero el predomino femenino no está sólo en las tramas argumentales. En todos los diálogos ella canta más versos que él, lo interrumpe, no lo deja hablar. Además, las líneas melódicas de ella siempre son más memorables y brillantes. De hecho, la voz de Lucía, mucho más potente y nítida en la emisión, predomina absolutamente en los estribillos que, además, buscan la parte más

\footnotetext{
${ }^{22}$ Cf. DE LA PEZA, María del Carmen. El bolero y sus formas de decir amor. In: Anuario UAM. México: Departamento de Educación y Comunicación de la UAM, 1999.

${ }^{23}$ Sobre el dispositivo de enunciación del teatro, ver DE TORO, Fernando. Semiótica del teatro: del texto a la puesta en escena. Buenos Aires: Galerna, 1987.

${ }^{24}$ Siguiendo a De Toro, la escena representada es la que involucra a los personajes sobre el escenario. La escena teatral relaciona a los actores y los espectadores.
} 
aguda del registro al tiempo que aumenta la intensidad. Es decir, todo lo que socialmente está asociado con un arranque de ira que se reconoce porque la persona enojada tiende a levantar la voz. De manera que lo que nos muestran las canciones de pelea son mujeres empoderadas y varones que, a pesar de la posición dominante de los varones en las relaciones matrimoniales, se muestran vulnerables e impotentes. Los propios hermanos Galán hablan de la respuesta afectiva que generaban estas canciones en el público femenino: empatía y solidaridad con los personajes que representa Lucía. Los shows llegaban a ser la ocasión de la humillación ritual y colectiva de los personajes que representa Joaquín. En palabras del propio Joaquín Galán: “En nuestras canciones la heroína siempre es la mujer que busca reivindicar su género. Su mensaje ni siquiera es para el hombre a quien le canta: es para ellas, para el machismo cultural que todavía padecen". ${ }^{25}$

\section{Las canciones de pelea y el inconsciente político}

En su ya clásico texto de 1989, Frederic Jameson abogaba por una lectura política de los textos narrativos como horizonte de toda interpretación. Ese horizonte supone una filosofía de la historia "capaz de respetar la especificidad y la radical diferencia del pasado social y cultural, a la vez que revela la solidaridad de sus polémicas pasiones, sus formas, estructuras, experiencias y luchas, con las de la época presente" ${ }^{26}$ Esa mirada parte de dos principios. En primer lugar, la idea de que hay una cierta unidad en la historia humana, una gran lucha colectiva por arrancar, parafraseando a Marx, un reino de la Libertad al reino de la Necesidad. En otros términos, habría una continuidad fundamental de las luchas emancipatorias. Según Jameson, “en la restauración en la superficie del texto de la realidad reprimida y enterrada de esa historia fundamental, es donde la doctrina de un inconsciente político encuentra su función y necesidad". ${ }^{27}$ Desde ese punto de vista, no habría una diferencia entre textos culturales que son políticos y otros que no lo son, puesto que esa distinción potencia la brecha entre lo individual y lo político, entre lo público y lo privado, cercenando nuestra experiencia. Y esto nos lleva al segundo principio, la necesidad de considerar los textos culturales como "actos socialmente simbólicos" ${ }^{28}$ Esto es, a partir del análisis de las estructuras, complejas y contradictorias de todo texto cultural, se puede acceder a las contradicciones sociales tal como están narrativizadas en el inconsciente político. Para ello Jameson propone un modelo analítico de tres horizontes o círculos concéntricos. En un primer horizonte propone un análisis formal de las obras, recuperando la semiótica greimasiana, para detectar el sistema de oposiciones sémicas binarias, pero pensándolo en términos de contradicciones. En el segundo horizonte, esas estructuras que revela el análisis inmanente, se ponen en relación con el sistema de las relaciones sociales. De tal manera, "la producción de una forma estética o narrativa debe verse como un acto ideológico por derecho propio, con la función de inventar 'soluciones' imaginarias o formales a

\footnotetext{
${ }^{25}$ GALAN, Lucía y GALAN, Joaquín, op. cit., p. 116.

${ }^{26}$ JAMESON, Frederic, op. cit., p. 16.

${ }^{27}$ Idem, ibidem, p. 17.

${ }^{28}$ Idem, ibidem, p. 18.
} 
contradicciones sociales insolubles" ${ }^{29}$ La detección de esas relaciones entre el texto y las contradicciones sociales supone, claro está, salir de la inmanencia y abordar la discursividad social de un modo más amplio. En el tercer horizonte, finalmente, el sistema de contradicciones sociales expresado en los discursos, se pone en relación con los procesos históricos de largo plazo.

El modelo de análisis que propone Jameson puede ser operativo para pensar las canciones de pelea, a condición de tomar distancia en dos aspectos cruciales. Por una parte, Jameson mantiene del marxismo clásico la idea de que los procesos de largo plazo se estructuran alrededor de la lucha de clases y la sucesión de modos de producción. Sin embargo, desde la emergencia de corrientes teóricas contemporáneas como los estudios subalternos, el enfoque decolonial y las diversas corrientes del feminismo, sabemos que la explotación de clase no es la única fuente de desigualdad en las sociedades modernas. Así pues, si se consideran diferentes ejes de subalternidad como el género, la raza, o la dependencia colonial, el universo de la conflictividad social se amplía notoriamente y aparecen otro tipo de contradicciones que también se narrativizan en el inconsciente político. Por otra parte, el modo de Jameson de pensar una producción cultural como acto ideológico, requiere tomar distancia de algunas connotaciones muy criticadas del concepto de ideología. Desde hace un tiempo ha habido un movimiento de recuperación de dicho concepto desde diversos cruces con el psicoanálisis. ${ }^{30}$ Sin embargo, el término conserva la connotación de referirse al mundo de las ideas o, incluso, de la textualidad. Pero ese privilegio de la textualidad ha sido cuestionado desde hace varios años. Desde la emergencia de la corriente que ha recibido el nombre englobante de "giro afectivo" los estudios sobre música popular vienen volviendo su mirada hacia la circulación de afectos y emociones en relación con las canciones. ${ }^{31} \mathrm{Y}$ esto permite abordar aspectos más sutiles, no necesariamente cristalizados en un discurso sistemático, pero que sin embargo forman una parte sustantiva de la capacidad de interpelación de las canciones y de la producción de sentido que se da en los procesos de recepción. ${ }^{32}$

Teniendo en cuenta esos recaudos, se puede pensar las canciones de pelea como expresiones y resoluciones simbólicas de un conflicto social emergente en la Argentina a principios de los ochenta, que indirectamente estaba relacionado también con la crisis de la dictadura y las demandas de democratización. Pero esas expresiones y resoluciones simbólicas tenían que ver más con transformaciones en la esfera de los sentimientos y las emociones que en la de los sistemas de ideas; y con las relaciones entre los géneros, más que con la lucha de clases.

Si bien no tengo espacio aquí para un análisis sistemático de las canciones, quisiera al menos esbozar la manera en que está construido el conflicto en "Olvídame y pega la vuelta" retomando algunas herramientas greimasia-

\footnotetext{
${ }^{29}$ Idem, ibidem, p. 64.

${ }^{30}$ Ver ŽIŽEK, Slavoj (comp.). Ideología: un mapa de la cuestión. México-Argentina-Brasil-Colombia-ChileEspaña-Estados Unidos-Guatemala-Perú-Venezuela: Fondo de Cultura Económica, 2003, y CARPINTERO, Enrique (comp.). Actualidad del fetichismo de la mercancía. Buenos Aires: Topía, 2013.

${ }^{31}$ Sobre el giro afectivo en los estudios sobre música popular, ver VILA, Pablo. Music, dance, affect, and emotions in Latin America. Lanham: Lexinton Books, 2017.

32 Ver DÍAZ, Claudio y MONTES, María de los Ángeles. Músicas populares, cognición, afectos e interpelación: un abordaje socio-semiótico. El Oído Pensante, 8/2, ago. 2020-ene., 2021.
} 
nas. ${ }^{33}$ En este caso, la mujer narra la pérdida de un objeto de valor $(\mathrm{OV})$ que es la relación matrimonial: "Hace dos años y un día que vivo sin él". Pero también se presenta un proceso de adquisición de un saber vinculado a la autonomía como nuevo OV: "Y aunque no he sido feliz / aprendí a vivir sin su amor". Ese nuevo valor es el que resulta puesto en peligro cuando él intenta regresar. De manera que el arranque de ira está vinculado al temor a la pérdida del valor recién adquirido, además de al rencor por el abandono. La justificación del marido también muestra una contradicción entre valores distintos: "En busca de emociones un día marché/ de un mundo de sensaciones que no encontré/ y al descubrir que era todo una gran fantasía volví/ porque entendí que quería las cosas que viven en ti". Como puede verse, en un lado de la oposición sémica están las emociones y sensaciones, que, según la canción, pertenecen al orden del parecer (la fantasía). Y en el otro, los valores de la relación matrimonial, encarnados en la esposa que, por oposición pertenecen al orden del ser, es decir de lo real. Esta oposición en el texto (que aparece en el análisis inmanente) se corresponde con una oposición ampliamente difundida en el discurso social aún en nuestros días. La oposición entre dos concepciones del amor, que implican dos morales y, en cierto sentido, dos mandatos sociales. Por una parte, el amor pasión, con su retórica hiperbólica del frenesí, la locura y la sensualidad, y por otra, el amor matrimonial, con su retórica de la familia y la estabilidad. ${ }^{34}$ De manera que ahora puede dimensionarse la magnitud del rechazo del personaje femenino de esta canción. Al negarse al retorno del marido, rechaza el amor matrimonial y rechaza el lugar que encarna como mujer en ese sistema de oposiciones. $Y$ lo hace en nombre del valor de la autonomía que descubrió tras el abandono.

Si bien en las canciones del dúo no hay un cuestionamiento explícito del matrimonio, lo que sí se puede decir es que muestran la crisis de una relación naturalizada en el mundo de la canción romántica: la relación que ve al amor romántico como fundamento del matrimonio heterosexual monogámico. Si bien no puedo detenerme en el análisis de esa relación, vale la pena al menos consignar algunos rasgos característicos: a) la relación amorosa es del orden de la pasión, y aparece textualizada con imágenes del "arrebato" o el "frenesí". Es decir, las "emociones" y "sensaciones" de las canciones del dúo; b) los amantes están predestinados uno al otro desde siempre. Por eso el encuentro es un "descubrimiento", un hecho que irrumpe en la vida ordinaria y la transforma. Esta idea de la búsqueda de una mitad faltante que resuelva una incompletud constitutiva tiene un origen antiguo, recogido por Platón en El banquete ${ }^{35}$; c) los amantes deben pasar pruebas y dificultades antes de triunfar, lo que remite a la retórica del amor cortés que pervive en los boleros y en las baladas románticas ${ }^{36}$; d) el triunfo final de los amantes se resuelve con la

\footnotetext{
${ }^{33}$ Sobre las herramientas de la semiótica greimasiana para el análisis de las pasiones, ver GREIMAS, A. J, y FONTANILLE, J. Semiótica de las pasiones: de los estados de cosas a los estados de ánimo. Puebla: Siglo XXI, 1994.

34 Sobre amor pasión, amor romántico y amor matrimonial, ver GIDDENS, Anthony. La transformación de la intimidad: sexualidad, amor y erotismo en las sociedades modernas. Madrid: Cátedra, 2008.

${ }^{35}$ Sobre la noción platónica de eros, ver HALPERIN, David. El éros platónico y lo que los hombres llaman amor. Journal of Ancient Philosophy, n. 5, São Paulo, 1985.

${ }^{36}$ Sobre la supervivencia de la retórica del amor cortés en los boleros, ver CUÉLLAR, Donaji. Supervivencias del amor cortés en el bolero hispanoamericano. Boletín de Literatura Oral, número extraordinario, n. 2,
} 
consumación del matrimonio, es decir la unión de los amantes en exclusividad heterosexual, que da lugar a la fundación de una familia. Con múltiples variantes, este es el esquema narrativo básico de infinidad de novelas, películas y canciones.

Ahora bien, esa idea del amor/pasión como fundamento del matrimonio es un desarrollo moderno que se asocia a profundas transformaciones políticas y económicas, y llegó a tener una funcionalidad específica. No se trata, claro, de que el matrimonio sea un invento moderno. Lo que es moderno es la idea de que el fundamento del matrimonio es el amor entendido de esa manera. Anthony Giddens ha señalado que la idea del amor romántico y el compromiso espiritual a largo plazo entre los amantes está relacionada con cambios en el status de las mujeres a partir del siglo XVII, principalmente por la separación entre la esfera de la producción (masculina) y el ámbito doméstico (femenino). ${ }^{37}$ Ese proceso está vinculado a su vez con la idealización de la maternidad como rasgo central de la femineidad.

Silvia Federici va más lejos ${ }^{38}$ : en discusión con Marx y su noción de "Acumulación originaria", sostiene que para la formación del capitalismo no sólo hacía falta el desarrollo de un mercado global y la acumulación de fuerza de trabajo asalariado. También hacía falta algo más que era fundamental: garantizar la reproducción de la fuerza de trabajo. Y para eso había que disciplinar a las mujeres, principalmente de las clases populares. De tal manera que se puede pensar que la vinculación de las ideas de amor romántico y matrimonio es parte de ese proceso, puesto que era necesario generar un núcleo de significaciones imaginarias poderosas, en términos de Castoriadis ${ }^{39}$, que hicieran ver como resultado del "amor" y la "naturaleza femenina" todo lo que se le arrebataba a las mujeres para disciplinarlas: se las excluía de los recursos, se las excluía del salario y se las sometía al poder del marido. Así como los varones se integraban por la fuerza a la maquinaria de producción, las mujeres se convertían en la máquina de reproducir y cuidar.

De manera que, siguiendo el modelo de Jameson, podemos ver que lo que expresan las canciones de pelea, enraíza en un proceso de largo plazo que atraviesa toda la modernidad. El dispositivo de enunciación de las canciones de pelea y el lugar de empoderamiento que se les adjudica a los personajes femeninos constituyen una novedad que interpelaba a las mujeres porque expresaba un profundo malestar, que mostraba, a su vez, un cambio emergente en las estructuras de sentimiento. Pero la crisis del matrimonio que se manifestaba a finales de la dictadura en la Argentina, y que las canciones de pelea expresaban, estaba ligada a esos procesos de largo plazo en la desigualdad de género y las luchas emancipatorias que la cuestionaban. Después de la segunda guerra mundial, cambios tales como la incorporación masiva de las mujeres al mundo del trabajo fueron generando condiciones para un cuestionamiento profundo del lugar de la mujer que empezó a hacerse muy visible hacia

\footnotetext{
Jaén, 2019. Para un análisis muy interesante, ya clásico, sobre la pasión en la literatura del amor cortés, y sus transformaciones en el mundo moderno, ver DE ROUGEMONT, Denis. El amor y occidente. Buenos Aires: SUR, 1959.

37 Ver GIDDENS, Anthony, op. cit., p. 43-52.

38 Ver FEDERICI, Silvia. Calibán y la bruja: mujeres, cuerpo y acumulación originaria. Madrid: Traficantes de Sueños, 2010.

${ }^{39}$ Ver CASTORIADIS, Cornelius, op. cit., p. 283-334.
} 
los años sesenta. Las transformaciones culturales que trajo aparejadas ese cuestionamiento tuvieron características particulares en la Argentina debido a los rasgos diferenciales de su proceso político.

\section{Sexualidad y género: un cambio en la estructura de sentimientos hacia el final de la dictadura}

La noción de estructura de sentimientos fue introducida por Raymond Williams como herramienta para comprender cambios en las sensibilidades. Cambios que resultan vividos o experimentados mucho antes de decantar en un discurso articulado. Desde su punto de vista este nivel de la experiencia es importante para comprender la emergencia de significados y valores que ya forman parte de las luchas hegemónicas y por lo tanto ejercen presiones sobre las subjetividades. En sus palabras:

[Estos cambios] son asumidos desde el principio como experiencia social antes que como experiencia "personal" o como el "pequeño cambio" simplemente superficial [...] Son sociales de dos maneras [...] primero, en el hecho de que son cambios de presencia; segundo en el hecho de que aunque son emergentes o preemergentes, no necesitan esperar una definición, una clasificación o una racionalización antes de ejercer presiones palpables y de establecer límites efectivos sobre la experiencia o sobre la acción. Tales cambios pueden ser definidos como cambios en las estructuras del sentir" [...] Las estructuras del sentir pueden ser definidas como experiencias sociales en solución, a diferencia de otras formaciones semánticas sociales que han sido precipitadas y resultan más evidentes y más inmediatamente aprovechables. ${ }^{40}$

Creo que las canciones de pelea del dúo Pimpinela, y su capacidad para interpelar al público principalmente femenino, pueden ser mejor comprendidas si se piensa en una transformación de ese tipo que estaba ocurriendo en la Argentina en esos años. Una transformación en la sensibilidad que afectaba muy ampliamente a la sexualidad y la relación entre los géneros, y en particular, el matrimonio. El fin de la dictadura y la recuperación de la democracia fue un proceso complejo en el marco del cual se pusieron en cuestión diversas dimensiones de una sociedad autoritaria y conservadora. En las memorias construidas sobre ese período ocupan un lugar central las luchas por los Derechos Humanos y la democratización de las instituciones. Pero también en materia de sexualidad y relaciones de género empezaban a notarse cambios sustantivos. En un trabajo reciente, la historiadora Natalia Milanesio ha estudiado un fenómeno ocurrido entre el final de la dictadura y el comienzo de la democracia, conocido como "El destape". ${ }^{41} \mathrm{El}$ destape fue un fenómeno mediático que consistió en una aparición masiva en diversos medios de comunicación de “imágenes y narrativas sexuales explícitas que apenas unos años atrás la dictadura habría considerado vulgares, inmorales, indecorosas y peligrosas". ${ }^{42} \mathrm{Y}$ junto con eso el consumo masivo de libros de sexología, terapias sexuales, y toda clase de productos culturales vinculados. Según la autora, se trató, ade-

\footnotetext{
${ }^{40}$ WILLIAMS, Raymond, op. cit., p. 156.

${ }^{41}$ Ver MILANESIO, Natalia. El destape: la cultura sexual en la Argentina después de la dictadura. Buenos Aires: Siglo XXI, 2021.

${ }^{42}$ Idem, ibidem, p. 11.
} 
más de un fenómeno mediático, de "un profundo proceso de transformación de ideologías y prácticas sexuales". ${ }^{43}$ Milanesio llama la atención sobre un hecho que es muy importante para mi argumento: si bien siempre hay algo del orden de lo político en la sexualidad, en algunos períodos ese aspecto de las relaciones sociales es cuestionado de un modo más abrupto y es politizado de manera más abierta. Este cuestionamiento, a principios de los ochenta, iba más allá de la sexualidad en sí y afectaba las formas de pensar el amor (y de cantar al amor), junto a instituciones ligadas a él como el matrimonio y la familia. Porque en ese período todos estos aspectos, igual que muchos otros, se fueron articulando con las demandas generales de democratización. Y esto como consecuencia de que durante la dictadura se habían impuesto violentamente las concepciones morales más conservadoras. Esas concepciones, en realidad, se habían ido afirmando en el discurso social antes de ella, como parte de lo que Andrés Avellaneda llama el "discurso de represión cultural". ${ }^{44}$ Ese discurso, que había ido tomando forma desde la dictadura del general Juan Carlos Onganía se centraba en la defensa de un estilo de vida que correspondía a la idea de una gran nación católica. ${ }^{45}$ Por lo tanto, se veía un peligro de infiltración ideológica en cualquier manifestación cultural que cuestionara de algún modo esos valores.

Ahora bien, durante los años sesenta, ese discurso se enfrentó simbólicamente a toda una producción cultural relacionada con la emergencia de la juventud como actor social importante, y que, más allá de sus profundas diferencias, tenía en común el cuestionamiento del orden moral de las generaciones anteriores. Pero la dictadura iniciada en 1976 llevó a su extremo un extendido sistema de censura cuyo objetivo era "subordinar todas las formas de expresión cultural a un tipo de moralidad que exaltaba el cristianismo, la familia, la modestia, el decoro, la defensa de los niños, la patria, el orden y la tradición" ${ }^{46}$ De manera que en ese período se interrumpió violentamente un proceso de transformación de las relaciones amorosas que, según Giddens, desde los sesenta estaba generando en las sociedades modernas una democratización de la esfera de la intimidad ${ }^{47}$ En ese proceso tenía un lugar central la progresiva liberación sexual de las mujeres que encontró en el desarrollo de la píldora anticonceptiva un símbolo de época.

Según Valeria Manzano, en la Argentina hubo varios factores que contribuyeron al protagonismo de las mujeres jóvenes en ese proceso. Para esta historiadora, "las 'chicas' [...] desafiaron en la práctica las nociones prevalentes del hogar mediante la prolongación de su estadía en el sistema educativo, la plena inserción en el mercado de trabajo, la participación en nuevas actividades para el esparcimiento juvenil, la disposición para experimentar nuevas convenciones de noviazgo o para reconocer en público su incursión en el sexo

\footnotetext{
${ }^{43}$ Idem.

${ }^{44}$ AVELLANEDA, Andrés. El discurso de represión cultural (1960-1983). Escribas, n. 3, Córdoba, 2005.

45 Onganía llegó al poder mediante un golpe de estado en el que derrocó al presidente constitucional Arturo Illia el 28 de junio de 1966. Se mantuvo como presidente de facto hasta 1970, cuando fue desplazado por otro general, Roberto M. Levingston. Según Avellaneda, durante su gobierno los sectores más conservadores ocuparon muchos cargos importantes en las áreas de educación y cultura. Ver ídem.

${ }^{46}$ MILANESIO, Natalia, op. cit., p. 29.

${ }^{47}$ Ver GIDDENS, Anthony, op. cit., p. 15-27.
} 
prematrimonial y la postergación del casamiento en relación con sus predecesoras". 48

Esa actitud más liberal en relación a la sexualidad contribuyó a desestabilizar, entre otras cosas "una doble moral que instaba a los hombres a adquirir experiencia sexual antes de casarse mientras exigía a las mujeres que preservaran su virginidad hasta la noche de bodas". ${ }^{49}$ Paralelamente, Manzano consigna que en la juventud de esa época se fueron desarrollando también masculinidades alternativas, como ocurrió por ejemplo con el rock. Si bien la comunidad rockera de ese período era una fraternidad fundamentalmente masculina, no desprovista de rasgos machistas, también es cierto que "los jóvenes cultores del rock impulsaron esa modernización por medio de valores como la igualdad y la autenticidad, que permitieron imaginar e incluso concretar nuevos proyectos de amor y de familia". ${ }^{50}$ Algunas de sus prácticas, como el uso de flores, ropas de colores y pelo largo provocaron, incluso, "una reacción homofóbica de múltiples sectores que se alzaron en defensa de la autoridad patriarcal y sus nociones establecidas de 'la moral y las buenas costumbres'”. .51

De manera que el pelo largo en los varones, y las minifaldas en las mujeres, se convirtieron en símbolos de esa búsqueda libertaria que se asociaba a una mayor igualdad $\mathrm{y}$, fundamentalmente, a una mayor autonomía de las mujeres. Según Manzano, esa progresiva autonomía, que generaba fuertes reacciones conservadoras, puede observarse en algunos datos muy significativos, como el aumento de la matrícula femenina tanto en la escuela media como en la universidad, y en la diversificación del tipo de empleo al que accedían las mujeres. Así, los tradicionales empleos femeninos, como el de maestra, por ejemplo, fueron dando lugar a nuevos empleos y nuevos modelos identitarios vinculados a ellos: empleadas de comercio, profesionales universitarias, secretarias ejecutivas. Para Manzano, "las chicas empleadas en empresas multinacionales que cobraban un buen sueldo, se vestían bien y participaban en actividades culturales de vanguardia eran minoría en el gran contingente de mujeres jóvenes que trabajaban fuera de la casa, pero encarnaban significados $\mathrm{y}$ aspiraciones del imaginario colectivo en torno a la modernidad y la independencia". ${ }^{52}$

En las diferentes producciones culturales, y entre ellas en la música popular, esos nuevos modelos de mujer empezaron a hacerse visibles. Así, por ejemplo, en 1969 Los Náufragos, una de las bandas pop más exitosas, editó "Yo en mi casa y ella en el bar", una canción en la que el enunciador masculino habla de una novia universitaria que participa en la esfera pública mientras él hace vida hogareña. ${ }^{53}$ Del mismo modo, en 1971 el cantautor Heleno, publi-

\footnotetext{
${ }^{48}$ MANZANO, Valeria. La era de la juventud en la Argentina: cultura, política y sexualidad desde Perón hasta Videla. México-Argentina-Brasil-Colombia-Chile-Ecuador-España-Estados Unidos-Guatemala-Perú-Venezuela: Fondo de Cultura Económica, 2017, p. 156.

${ }^{49}$ Idem, ibidem, p. 157.

${ }^{50}$ Idem, ibidem, p. 198.

${ }^{51}$ Idem.

${ }^{52}$ Idem, ibidem, p. 163.

${ }^{53}$ Los Náufragos fue una agrupación musical juvenil, cultora de una música pop, destinada a los jóvenes, que se consideró parte de la llamada "nueva ola" o música "beat". Debutó en 1969 y fue muy popular hasta mediados de los setenta. La canción "Yo en mi casa y ella en el bar" puede escucharse en $<$ https://www.youtube.com/watch?v=ycnKIM0M-nM>.
} 
có otro gran éxito, "La chica de la boutique", en la que el enunciador habla de ese nuevo modelo que encarnaban las empleadas de comercio representada por una chica con minifalda en la tapa del disco. ${ }^{54}$

Esas transformaciones en marcha son un elemento importante para explicar la virulencia de la reacción conservadora durante la dictadura en materia de moralidad, y la estrategia de vincular todo lo que los censores consideraban inmoral con la infiltración ideológica marxista. Milanesio menciona un episodio de 1980, cuando la Municipalidad de Buenos Aires incautó un número de una revista por exhibir una foto de una actriz en bikini: "La sanción respondía a la idea de que bikinis y minifaldas eran ofensas al decoro, desataban pasiones reprimidas, promovían la falta de respeto y la indecencia y disolvían los valores morales. Un artículo publicado en la Revista de Educación del Ejército concluía que, por todo esto, esas prendas de vestir disminuían las defensas de los individuos contra el marxismo". ${ }^{55}$

De manera que, así como el pelo largo en los varones y las minifaldas en las mujeres habían sido símbolos libertarios, pasaron a ser objeto de censura y represión. Y como contrapartida se construyó por todos los medios un modelo moral que tenía en su centro el matrimonio monogámico y patriarcal, en sus relaciones con el estilo de vida occidental y cristiano de la gran nación católica.

La violencia con que la dictadura interrumpió los procesos en curso a principios de los setenta explica por qué, hacia 1980, muchas prácticas culturales distintas (el rock, el teatro independiente, el humor o las revistas de historietas, por sólo nombrar algunas) se articularon alrededor de las demandas de democratización, en la medida en que todas las personas que participaban en ellas percibían en ese sistema moral, impuesto por la violencia, un enemigo común.

En ese contexto, muchas de esas producciones culturales empezaban a mostrar ese malestar de las mujeres que mencioné más arriba. Un malestar que se articulaba con las otras demandas de democratización, pero apuntaba particularmente a las relaciones matrimoniales, al lugar de la mujer en la familia, y a los procesos emancipatorios que la dictadura había interrumpido.

\section{Pégale Lucía: la voz de Lucía Galán y el malestar de las mujeres.}

En su libro autobiográfico los hermanos Galán cuentan que, en un show en Miami, mientras interpretaban una de las canciones de pelea, una mujer cubana se levantó en la platea al grito de “iPégale Lucía!”. ${ }^{66}$ La respuesta afectiva de la oyente expresa ese malestar y la fuerte identificación que generaban los personajes que Lucía ponía en escena y a los que les daba voz. El conflicto recurrente que mostraban las canciones de pelea, como dije antes, no puede interpretarse como un cuestionamiento explícito del matrimonio monogámico. Ni tampoco podría hablarse de una crítica directa al patriarcado,

\footnotetext{
${ }^{54}$ Heleno fue el nombre artístico del cantautor Miguel Angel Espinoza, cultor de la música "beat" que tuvo varios éxitos a principios de los setenta. "La chica de la boutique”, su hit más importante, puede escucharse en <https://www.youtube.com/watch?v=pgIK7uF5qMY\&list=RDpgIK7uF5qMY\&index=1>.

55 MILANESIO, Natalia, op. cit., p. 34.

${ }^{56}$ GALAN, Lucía y GALAN, Joaquín, op. cit., p. 84.
} 
concepto que, por lo demás, a principios de los ochenta estaba lejos de circular masivamente. Pero lo que sí mostraban las canciones de pelea eran mujeres empoderadas que levantaban su voz para confrontar a los varones. Y lo que les cuestionaban era el incumplimiento del contrato monogámico y la injusticia que eso conllevaba, pues ponía en escena esa doble moral que, como vimos venía siendo cuestionada desde los sesenta. Así, pues, volviendo a Jameson, las canciones de pelea proponían una resolución simbólica de un conflicto que en la realidad social estaba presente, pero lejos de resolverse. Sólo que no se trataba de un conflicto entre las clases sociales, sino de una crisis producida por la desigualdad entre los géneros. La resolución simbólica que proponían las canciones de pelea era un acto de "justicia" ante una institución matrimonial que crujía por todos lados. De manera que, así como Mercedes Sosa, al retornar al país, se convirtió en la voz de muchos silenciados (por el exilio, por las prisiones, por las desapariciones, etc.) y los rockeros eran portavoces de las juventudes disidentes, Lucía Galán también logró expresar la voz de muchas mujeres silenciadas. De ahí su importancia política que se hace más clara si las canciones de pelea se ponen en relación con otras zonas del discurso social que fueron contemporáneas.

Por ejemplo, en 1985 se inició un debate que derivaría en una gran batalla cultural: el debate por la modificación de la ley de divorcio, que se terminaría aprobando en 1987. Esa ley, cuya aprobación debió enfrentar una fuerte oposición de los sectores más conservadores encabezados por la iglesia católica, permitió a los divorciados y divorciadas volver a casarse, cosa que no podían hacer con la ley anterior. ${ }^{57}$

Ahora bien, el debate de la ley de divorcio era sólo un aspecto de un movimiento mucho más amplio de apertura en el que había una gran cantidad de elementos mezclados. En palabras de Williams, "en solución". ${ }^{58}$ Pero era difícil ver la politicidad de esos elementos en la medida en que la cuestión de género no tenía el lugar que tiene hoy en la agenda pública. Por lo cual esos elementos todavía no cristalizaban en un discurso organizado que les diera visibilidad, y particularmente visibilidad política. Sin embargo, eso no quiere decir que no tuvieran presencia en el discurso social y, específicamente en la cultura de masas. Sin ninguna pretensión de exhaustividad, y sólo a título ilustrativo, cito algunos ejemplos contemporáneos al ascenso de la fama del dúo Pimpinela: a) en el número 41 de la revista Humor, de agosto de 1980, se publicó una nota de María Elena Walsh titulada "Sepa por qué usted es machista". En la misma revista se publicaban por esos años los artículos de Cristina Wargon, que en clave humorística criticaba el machismo; b) la historieta Mafalda, cuyas tiras originales se habían publicado hasta 1973, y seguían teniendo gran circulación, solía presentar chistes sobre la condición de esclava de la madre de la niña; c) entre 1979 y 1983 la revista Skorpio, de editorial Records, publicó una historieta titulada Bárbara, con guión de Ricardo Barreiro y dibujos de Juan Zanotto. Se trataba de una historia de ciencia ficción postapo-

\footnotetext{
${ }^{57}$ La Ley 23.515, conocida como Ley de divorcio vincular, fue sancionada el 12 de junio de 1987, bajo la presidencia de Raúl Alfonsín. La legislación anterior permitía el divorcio, pero no permitía a las personas divorciadas volver a casarse, con lo que se generaban muchos inconvenientes, para los hijos, la adquisición y herencia de bienes conyugales, etc. Alrededor de la sanción de esta ley se generó un gran debate.

58 WILLIAMS, Raymond, op. cit., p. 39.
} 
calíptica, que ha sido leída en clave política porque narra un proceso de resistencia a una invasión, en la tradición de El "eternauta", de Héctor Oesterheld. ${ }^{59}$ La particularidad consiste en que la líder de esa rebelión era una joven que deviene revolucionaria después de ser expulsada de su clan por resistirse a una violación ritual. Además, tiene una actitud sexual libre y en algunas partes aparece explícitamente la cuestión de la crítica al machismo; d) desde 1983 comenzó a emitirse por canal 11, la segunda época del programa "Matrimonios y algo más", de Hugo Moser. En ese programa se abordaban diversos aspectos del matrimonio en tono humorístico. Y no estaban ausentes las críticas al machismo. Por ejemplo, un personaje que encarnaba Mirta Busnelli era una feminista que desde un programa de radio invitaba a la liberación de la mujer; e) también empezaron a circular en la cultura de masas discursos que abordaban relaciones eróticas homosexuales, como es el caso de la película Adiós, Roberto, estrenada en 1985 y protagonizada por Carlos Calvo y Víctor Laplace.

Es decir que había en el discurso social una buena cantidad de indicios de que las relaciones de género y en particular las relaciones matrimoniales, en la versión que había sido dominante, estaban siendo cuestionadas, y se estaba produciendo la emergencia de nuevas miradas y nuevas sensibilidades, que guardaban relación con los procesos de las décadas anteriores. Pero esas nuevas sensibilidades, esos nuevos significados y valores, para decirlo en términos de Williams, estaban todavía "en solución", todavía no se habían estructurado en un discurso orgánico y articulado. Pertenecían todavía a lo que Javier Cristiano, siguiendo a Bloch, llama lo "todavía-no-consciente". ${ }^{60}$

Hacia el final de la dictadura y en la época de la transición democrática todos estos significados y valores convivían con la emergencia de nuevas sensibilidades críticas que en las décadas siguientes encontrarían formas discursivas articuladas y darían lugar a sucesivos debates sociales que tendrían como consecuencia importantes cambios en la legislación. En 1987, como dijimos, se modificó la Ley de divorcio; en 1991 se sancionó la Ley de cupo femenino; en 2010, la ley de matrimonio igualitario; en 2012, la ley de identidad de género. ${ }^{61}$

Lo que sostenemos, es que la respuesta afectiva que obtuvieron las canciones de pelea del Dúo Pimpinela desde principios de los 80 , se debe a que muchas mujeres encontraron allí un modo de expresar un malestar que

\footnotetext{
59 "El eternauta" fue una historieta con guión de Héctor Oesterheld y dibujos de Francisco Solano López. Se publicó originalmente en la revista Hora Cero entre 1957 y 1959. La historieta se trataba de una invasión extraterrestre y la heroica resistencia de los sobrevivientes en la ciudad de Buenos Aires. Fue interpretada como una alegoría de la resistencia peronista durante la proscripción y el exilio de Perón, posterior a 1955. Con el tiempo alcanzó una dimensión mítica como símbolo cultural del peronismo, y esa dimensión fue alimentada porque Oesterheld fue secuestrado por la dictadura en 1977 y está desaparecido desde entonces. ${ }^{60}$ Cf. CRISTIANO, Javier. Imaginación y acción social: elementos para una teoría sociológica de la creatividad. Buenos Aires: Ciccus, 2017, p. 37-60.

${ }^{61}$ La ley 24.012, de cupo femenino, se sancionó en noviembre de 1991, durante la presidencia de Carlos Menem, y estableció que un mínimo del $30 \%$ de los candidatos a cargos electivos deben ser mujeres. Esa ley abrió un cauce de participación de las mujeres en la política, muy importante hasta hoy. La Ley 26.618, conocida como de matrimonio igualitario, se aprobó el 15 de julio de 2010, bajo la presidencia de Cristina Fernández, y permitió por primera vez la unión civil entre personas del mismo sexo. La Ley 26.743, conocida como ley de identidad de género, se sancionó en mayo de 2012, bajo la presidencia de Cristina Fernández, establece el derecho de las personas a ser tratadas, incluso en la documentación, según la identidad de género autopercibida.
} 
todavía no tenía un discurso en el que pudiera ser nombrado y pensado. Todavía las luchas del feminismo no habían logrado poner en la agenda pública las conceptualizaciones del patriarcado que hoy ocupan un lugar central. Permítaseme citar en extenso el testimonio de Lucía Galán:

considero que el gran punto a favor para nuestra escalada de popularidad fue el personaje que yo encarnaba. A principios de los 80, la realidad de las mujeres era muy distinta de las escenificaciones que cantaba yo: mi personaje no sólo no permitía la mentira, la traición y el engaño, sino que además rechazaba el machismo, tan arraigado en esa época [...] fui de un día para otro, la "heroína" de las latinas sumisas del continente: las que agachaban la cabeza y no se atrevían a mirar a los ojos a sus maridos. Las que vivian sometidas [...] por el poder que les daba ser ellos los que ganaban dinero [...] habilitándolos a tener amantes y ser culturalmente aceptados por la sociedad. ${ }^{62}$

Las canciones de pelea expresaban ese malestar de las mujeres que estaba allí, en solución. Un malestar que anunciaba cambios en las sensibilidades, significados y valores, que pertenecían al orden de lo todavía-noconsciente, pero que ya se empezaban a manifestar. Para decirlo en términos de Jameson, ya tenían un lugar en el inconsciente político. Y, en los shows del Dúo Pimpinela, el ritual de las canciones de pelea ofrecía una suerte de resolución simbólica a un conflicto que en la realidad estaba (aún está) lejos de resolverse.

Texto recebido em 24 de setembro de 2021. Aprovado em 19 de outubro de 2021.

${ }^{62}$ GALAN, Lucía y GALAN, Joaquín, op. cit., p. 81. 